\title{
The influence of corneal density and thickness on tonometry measurement with goldmann applanation, non-contact and iCare tonometry methods
}

\author{
Ahmed Lubbad (D) - Irene Oluwatoba-Popoola - Melanie Haar - Carsten Framme • \\ Anna Bajor
}

Received: 29 July 2021 / Accepted: 3 January 2022/Published online: 13 January 2022

(C) The Author(s) 2022

\begin{abstract}
Purpose To evaluate the effect of corneal density and thickness on the accuracy of tonometry readings obtained via three most used techniques.

Method Intraocular pressures of 45 patients' right eyes were measured using Goldmann Applanation, iCare, and non-contact tonometry methods. Corneal parameters were obtained using the Pentacam Camera System. Data obtained were analyzed using Paired $t$ Test, Pearson's correlation coefficient, multiple linear regression analysis, and Bland-Altman plots.

Results The mean corneal thickness was $545.4 \pm 3.93 \mu \mathrm{m}$. The mean corneal density of total, stromal, $0-2 \mathrm{~mm}$, and $2-6 \mathrm{~mm}$ zones were $27.85 \pm 6.23 \quad$ GSU, $24.61 \pm 6.05 \quad$ GSU, $20.76 \pm 2.96 \mathrm{GSU}$, and $20.81 \pm 3.51 \mathrm{GSU}$ respectively. IOP readings had a statistically significant correlation with corneal stromal thickness, as well as with total and stromal density. The stromal density, however, showed higher correlation with the three tonometry methods than did the total density (iCare: -.482 (0.001) stromal density versus - .464 (0.001) total density, NCT: $-.376(0.011)$ versus -.353
\end{abstract}

A. Lubbad $(\varangle) \cdot$ I. Oluwatoba-Popoola .

M. Haar - C. Framme · A. Bajor

Clinic for Ophthalmology, Hannover Medical School,

Hannover, Germany

e-mail: Lubbad.Ahmed@mh-hannover.de

A. Lubbad

Carl-Neuberg-Str. 1, 30625 Hannover, Germany
(0.017), GAT: $-.306(0.041)$ versus - .296(0.048)). Statistical differences were found in comparing the iCare readings with GAT $(P<0,00)$ and with NCT $(P<0,00)$, with mean differences of $1.8 \mathrm{mmHg} \pm$ 2.6 and $2.0 \mathrm{mmHg} \pm 2.6$ respectively. GAT and NCT measurements showed no statistical difference $(P>0.05)$.

Conclusion This study shows that both central corneal thickness and stromal density are significant influential factors of reliable IOP readings. It is necessary to consider more corneal biomechanical properties, as well as exercise a high degree of caution in any new attempts towards adjusting an IOPcorrection equation.

Keywords Intraocular pressure - Tonometry · Corneal densitometry · Central corneal thickness . Glaucoma

\section{Introduction}

Glaucoma is a multifactorial disease which is diagnosed by evaluating multiple parameters such as intraocular pressure (IOP), visual fields loss, and thinning of the retinal nerve fiber (RNFL). An accurate measurement of IOP is key not only in detecting Glaucoma but also in evaluating the efficacy of a chosen therapy. It is the only risk factor capable of 
being medically altered in order to slow or stop the asymptomatic progression of this disease.

Goldman applanation tonometry (GAT) has been accepted as the gold standard method of measuring IOP since its invention in 1957 [1]. GAT obtains IOP readings by applying a different amount of mechanical pressure to flatten a pre-measured corneal surface area. Over the past years, different methods have been used to measure IOP. A new routine clinical examination is the Non-Contact Tonometry (NCT), which uses the general principle of Zeiss of Aerotonometry to obtain measurements without touching the globe of the eye [2]. A relatively new method of rebound tonometry most ideal for children and supine patients developed by Kantiola in a hand-held device called iCare measures IOP by detecting the motion of a magnetized probe in a solenoid. High IOP causes shorter stroke time of the probe. Six readings were taken and an average value was generated automatically. The tonometer has a built-in system to indicate if there is any discrepancy among these 6 readings. Whenever an error sign (bar) appeared, a new set of readings was taken. Measurements were conducted on the central cornea. Several studies have identified the influence of different biomechanical and material corneal properties such as corneal thickness, on these three tonometry methods [3-7].

The cornea is a complex tissue mainly made of extracellular matrix components. The physical and biochemical properties of these components are responsible for maintaining their mechanical structure. Collagen fibers and elastin in this tissue are developed and differentiated in a manner conferring strength, elasticity, and optical transparency. Irregularities in the corneal components bring about changes in its clarity and as a result, in its mechanical strength [8].

Oculus pentacam (Oculus Optikgeräte $\mathrm{GmbH}$, Wetzlar, Germany) is a Scheimpflug principle-based, non-invasive imaging system of the ocular anterior segment. A newly added feature to the standard pentagram software provides corneal densitometry analysis by producing a corneal density map of the backscattered light in different areas of the cornea [9]. Using a blue light source, it captures a series of 25 images from which a densitometry map is generated. A Grayscale unit (GSU) is used to describe the density, ranging from $0 \mathrm{GSU}$ of minimum light scattering to 100 GSU of maximal light scattering. In addition to generating four corneal diameter zones of $0-2 \mathrm{~mm}$, 2-6 $\mathrm{mm}, 6-10 \mathrm{~mm}$, and $10-12 \mathrm{~mm}$ from the central apex, it divides the cornea into three layers; anterior, central, and posterior which represent the epithelium, stroma, and endothelium respectively.

In this study, we evaluate the influence of total, stromal (center layer), 0-2 $\mathrm{mm}$, and 2-6 mm corneal density zones, as well as central corneal thickness in the accuracy of IOP measurements using three different tonometry methods.

\section{Method}

This prospective, observational study was carried out at the Medical School Hannover (MHH) in keeping with the tenets of the 1964 Helsinki Declaration, after gaining approval from the local ethics committee.

A total of 45 patients with glaucoma, ocular hypertension or observable papillary excavation, who underwent a hospital-based day-and-night profile of IOP measurements in our clinic were included. Subjects with corneal disease, degenerations or dystrophies, previous ocular surgery or trauma, ocular inflammation were excluded from the study.

After obtaining informed consent, measurement procedures with the Oculus Pentacam (Oculus Optikgeräte $\mathrm{GmbH}$, Wetzlar, Germany) were carried out prior to IOP measurements, to acquire the values of central corneal thickness (CCT) and corneal density. The tonometry values were obtained using the already calibrated tonometers NCT (CT-800, Topcon, Tokyo, Japan), iCare (iCare PRO, Tiolat Oy, Helsinki, Finland), and GAT (Haag Streit AG, Bern, Switzerland) respectively. GAT and iCare measurements were performed by the same doctor (A.L), while NCT was done by an ancillary staff. The average of three NCT values for each eye was used for the study. A drop each of Thilorbin ${ }^{\circledR}$ (Oxybuprocaine Hydrochloride $0,4 \%$ and Fluorescein Sodium 0,8\%) eye drops was instilled in the eyes before carrying out GAT. GAT was performed last in the sequence of examinations to avoid induced changes in pentagram images and subsequent IOP readings. GAT readings were just obtained once to avoid a corneal-compression-induced aqueous outflow increase that would have affected subsequent IOP readings.

Statistical Package for the Social Sciences (IBM SPSS ${ }^{\circledR}$ Chicago, IL, USA) was used to perform the 
Table 1 Differences and correlations among IOP readings

\begin{tabular}{llll}
\hline & Paired samples test & Differences $\pm \mathrm{SD}$ & $\mathrm{r}^{p}(\mathrm{P}$ Value $)$ \\
\hline iCare-GAT & $\mathrm{P}<0.05$ & $1.8 \mathrm{mmHg} \pm 2.6$ & $0.736(<0.05)$ \\
iCare-NCT & $\mathrm{P}<0.05$ & $2.0 \mathrm{mmHg} \pm 2.6$ & $0.77(<0.05)$ \\
GAT-NCT & $\mathrm{P}=0.659023$ & $0.15 \mathrm{mmHg} \pm 2.3$ & $0.813(<0.05)$ \\
\hline
\end{tabular}

statistical analysis. In the Intraclass correlation coefficient (ICC) test of pachymetry and densitometry values were highly correlated. Because Intraclass Correlation was high ( $\geq 0.9$ for all parameters except for density zone $0-2 \mathrm{~mm} \mathrm{0.864),} \mathrm{we} \mathrm{analysed} \mathrm{the} \mathrm{data}$ from right eyes only, to avoid artificially reduced standard deviations. Paired samples t-Test was performed to compare the means of the three tonometry methods. The relationship between CCT and density and the three IOP readings were evaluated by Pearson's correlation coefficient. Multiple linear regression analysis was performed for the IOP measurements, corneal thickness, and density. In addition, Bland-Altman plots were performed to observe the agreement in IOP readings among the three tonometry methods (Tables 1,2 ).

\section{Results}

Our study included 45 right eyes of patients with or without glaucoma with a mean age of $61.62 \pm 17.64$ (median 65). There was no statistical difference between measurements obtained using GAT and NCT procedures $(P>0.05)$. Statistical differences were found in comparing the iCare readings with GAT, with a mean difference of $1.8 \mathrm{mmHg} \pm 2.6$, and with NCT, with a mean difference of $2.0 \mathrm{mmHg} \pm 2.6$. All three methods were however highly correlated (Fig. 1, Table 2).

We found no effect of gender and age on IOP or CCT readings. Age though significantly affected the density values. Total and stromal density were highly correlated with age $\left(\mathrm{r}^{\mathrm{p}} 0.761\right.$ and 0.754 respectively, $P<0.01$ ). The density zones of $0-2 \mathrm{~mm}$ and $2-6 \mathrm{~mm}$ were less correlated with age $\left(\mathrm{r}^{\mathrm{p}} 0.424,0.572\right.$ respectively). This correlation was statistically significant $(P<0.01)$. The mean corneal thickness was found to be $545.4 \pm 3.93 \mu \mathrm{m}$ (median $542 \mu \mathrm{m}$ ). The mean corneal density of total, stromal, $0-2 \mathrm{~mm}$, and $2-6 \mathrm{~mm}$ zones were $27.85 \pm 6.23$ GSU, $24.61 \pm 6.05$ GSU, $20.76 \pm 2.96$ GSU, and $20.81 \pm 3.51$ GSU respectively (Fig. 2). There was a statistically significant correlation between IOP readings and CCT, total and stromal density (Figs. 3 and 4). Both 0-2 $\mathrm{mm}$ and $2-6 \mathrm{~mm}$ density zones were not significantly correlated to any tonometry method. Stromal density showed higher correlation with the three tonometry methods than did the total density.

CCT showed a significant negative correlation with the total, stromal, and the 2-6 mm density zones, but not with the $0-2 \mathrm{~mm}$ zones (Fig. 5). All Pearson and $\mathrm{p}$ values are represented in Table 2. Because of high correlations among the density values of total, stromal, zone $0-2$, and zone $2-6 \mathrm{~mm}$, the stromal density alone was used in multiple linear regression analysis to avoid multicollinearity.

The linear regression analysis showed significant correlations between IOP readings \& CCT, as well as between IOP readings \& stromal density. A multiple regression analysis accepted both CCT and stromal density as predictors in ANOVA-Test for Regression ( $p$ value 0.038 for GAT, $<0.001$ for iCare and NCT) Significant correlations were found in the coefficients-
Table 2 Pearson correlation between IOP readings to $\mathrm{CCT}$ and density values ( $p$ values)

\begin{tabular}{llllll}
\hline & CCT & Total density & Stromal density & 0-2 mm zone & 2-6 mm zone \\
\hline iCare & $.479(0.001)$ & $-.464(0.001)$ & $-.482(0.001)$ & $-.109(0.475)$ & $-.290(0.053)$ \\
NCT & $.484(0.001)$ & $-.353(0.017)$ & $-.376(0.011)$ & $-.203(0.181)$ & $-.228(0.133)$ \\
GAT & $.329(0.027)$ & $-.296(0.048)$ & $-.306(0.041)$ & $-.060(0.693)$ & $-.159(0.295)$ \\
CCT & - & $-0.35(0.017)$ & $-.408(0.005)$ & $-.267(0.077)$ & $-.310(0.038)$ \\
\hline
\end{tabular}


Fig. 1 Bland-Altman plots that show differences between a iCare-GAT, b iCare-NCT, and c GATNCT tonometry measurements. Statistical differences were found in comparing the iCare-GAT readings with both GAT and NCT with a mean difference of (a) $1.8 \mathrm{mmHg} \pm 2.6$ and (b) $2.0 \mathrm{mmHg} \pm 2.6$, respectively $(P<0.05)$. There was no statistical difference between GAT and NCT measurements (c) $0.15 \pm 2.3, P>0.05$. The middle line indicates mean difference (bias); upper and lower lines, 95\% of limits of agreement
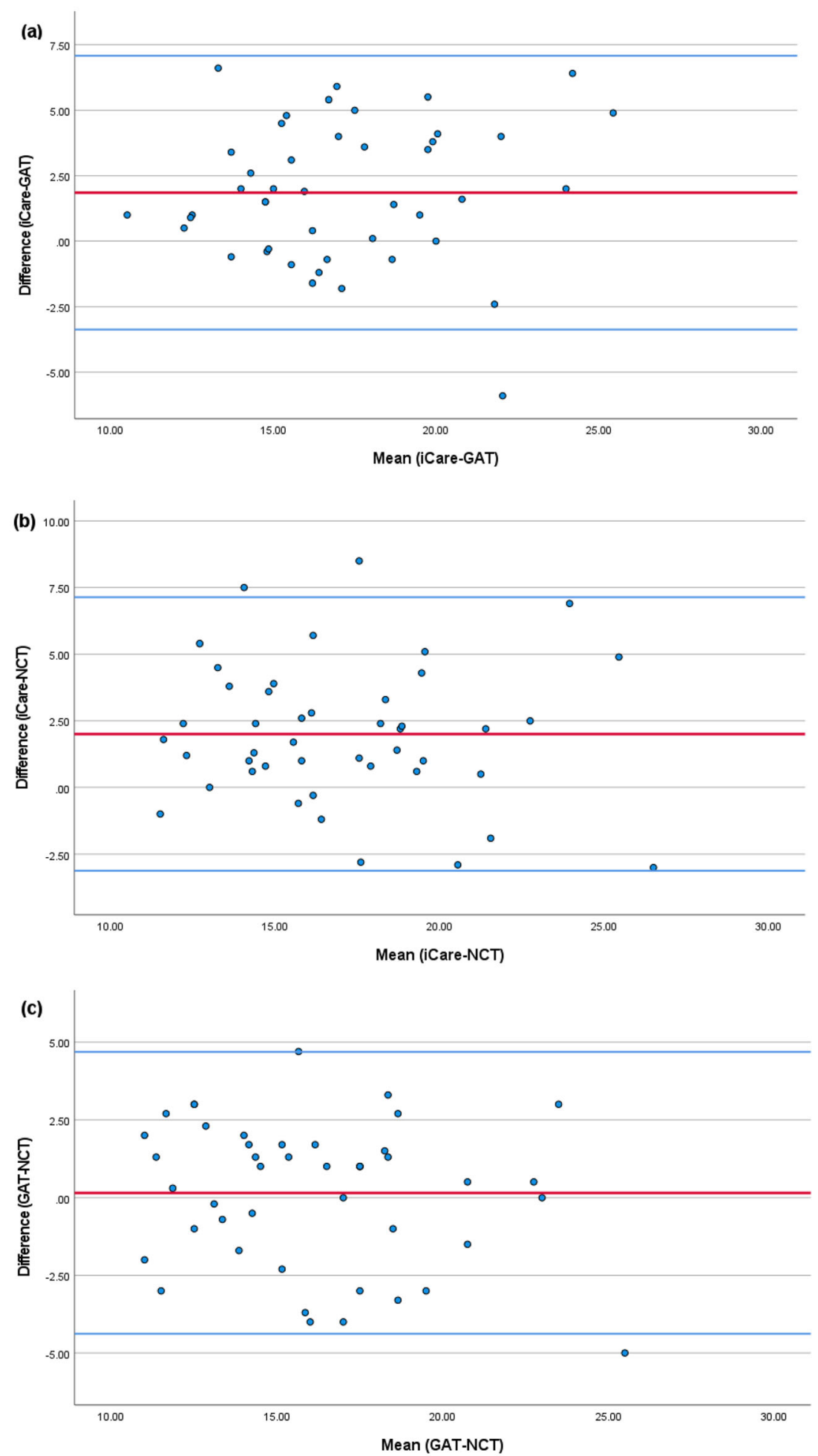
Fig. 2 Box plot of corneal densitometry measurements. The mean corneal density of total, stromal, 0-2 $\mathrm{mm}$ and 2-6 $\mathrm{mm}$ zones were $27.85 \pm 6.23 \mathrm{GSU}$ $24.61 \pm 6.05 \mathrm{GSU}$, $20.76 \pm 2.96 \mathrm{GSU}$, and $20.81 \pm 3.51 \mathrm{GSU}$ respectively

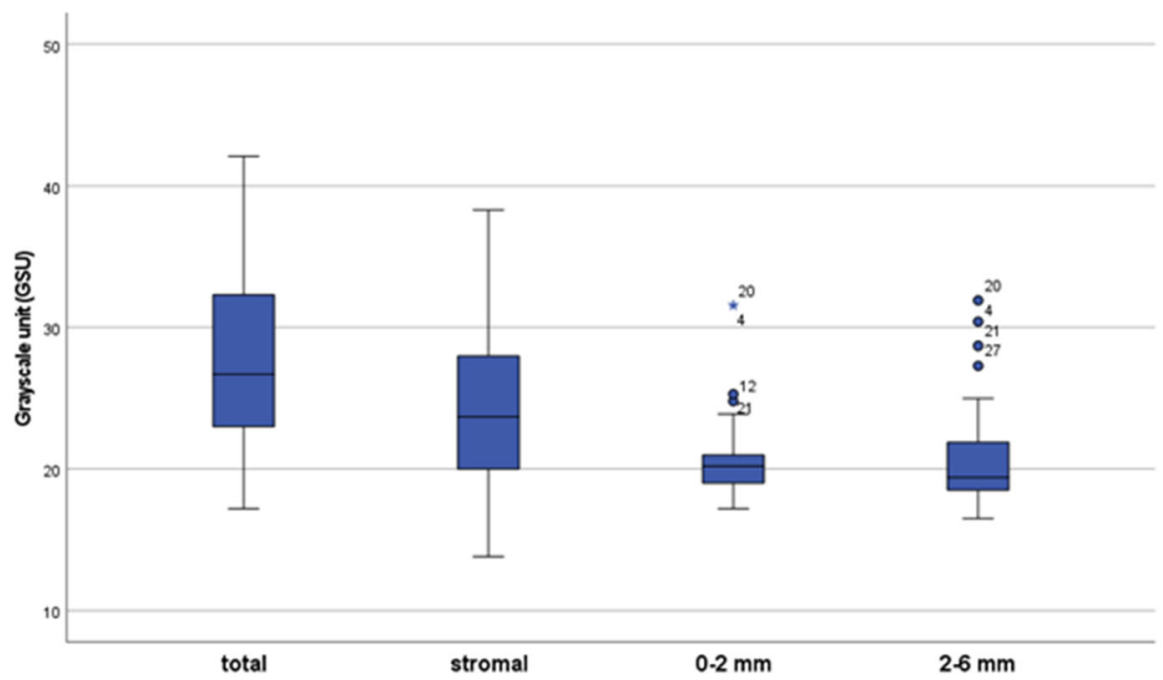

Fig. 3 Correlation among IOP readings obtained by GAT in blue $(0.329,0.027)$, iCare in green $(0.479,0.001)$, and NCT in red solid lines $(0.484,0.001)$ to CCT were statistically significant of $r$ Pearson and $\mathrm{P}-$ Value respectively

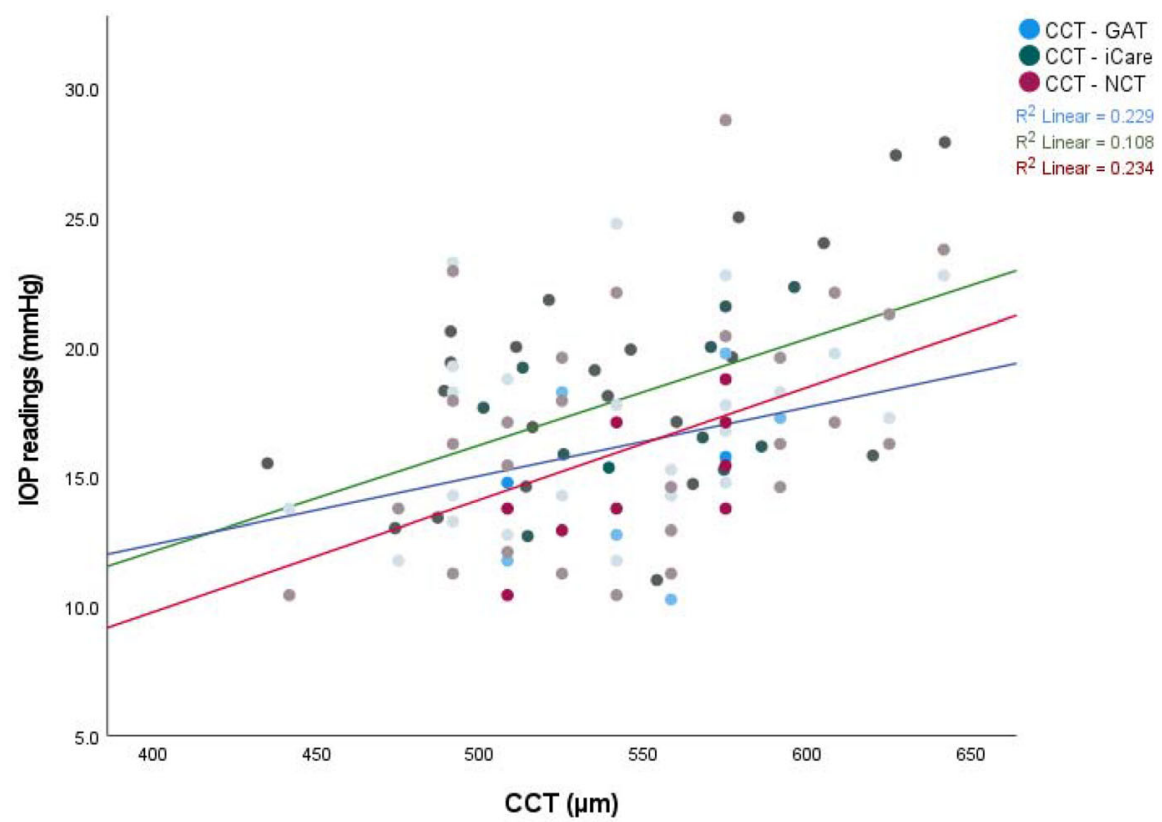

test between iCare and CCT $(P$ value 0.019 , partial correlation 0.353$)$ and stromal density $(P$ value 0.017 , partial correlation -0.358$)$. NCT readings showed a significant correlation with CCT $(P$ value 0.009 , partial correlation 0.39 ), but were not significantly correlated to stromal density ( $P$ value 0.144 , partial correlation - 0.224). Finally, in the GAT readings, a multiple regression analysis rejected both CCT and stromal density ( $P$ values 0.125 and 0.195 ), with a partial correlation of 0.235 and -0.199 respectively.

\section{Discussion}

IOP evaluation is one of the most important clinical examinations in Ophthalmology, which can most accurately be measured by an invasive manometry. This led to the development of different measurement systems during the last century. In this study, iCare readings were significantly higher than the IOP readings obtained by GAT and NCT. In accordance with other studies, our results confirm overestimation of IOP in iCare readings when compared to GAT 
Fig. 4 IOP readings obtained by GAT in blue $(-0.306,0.041)$, iCare in green $(-0.482,0.001)$, and NCT in red solid lines $(-0.376,0.011)$ showed a statistically significant correlation to stromal density of $r$ Pearson and $P$ Value respectively

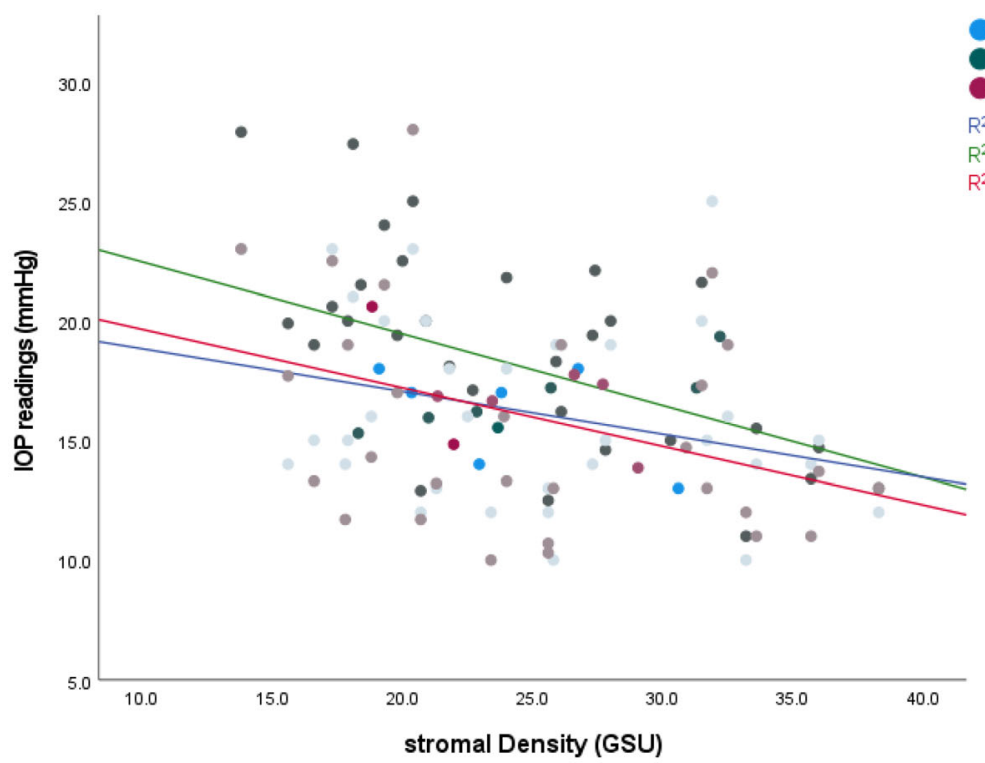

DenCent - GAT

DenCent - iCare DenCent - NCT

$R^{2}$ Linear $=0.233$

$\mathrm{R}^{2}$ Linear $=0.094$

$\mathrm{R}^{2}$ Linear $=0.141$
Fig. 5 CCT values were negatively correlated to both total in green $(-0.354$, $0.17)$ and stromal density in blue solid lines $(-0.408$, $0.005)$ of $r$ Pearson and $P$ Value respectively

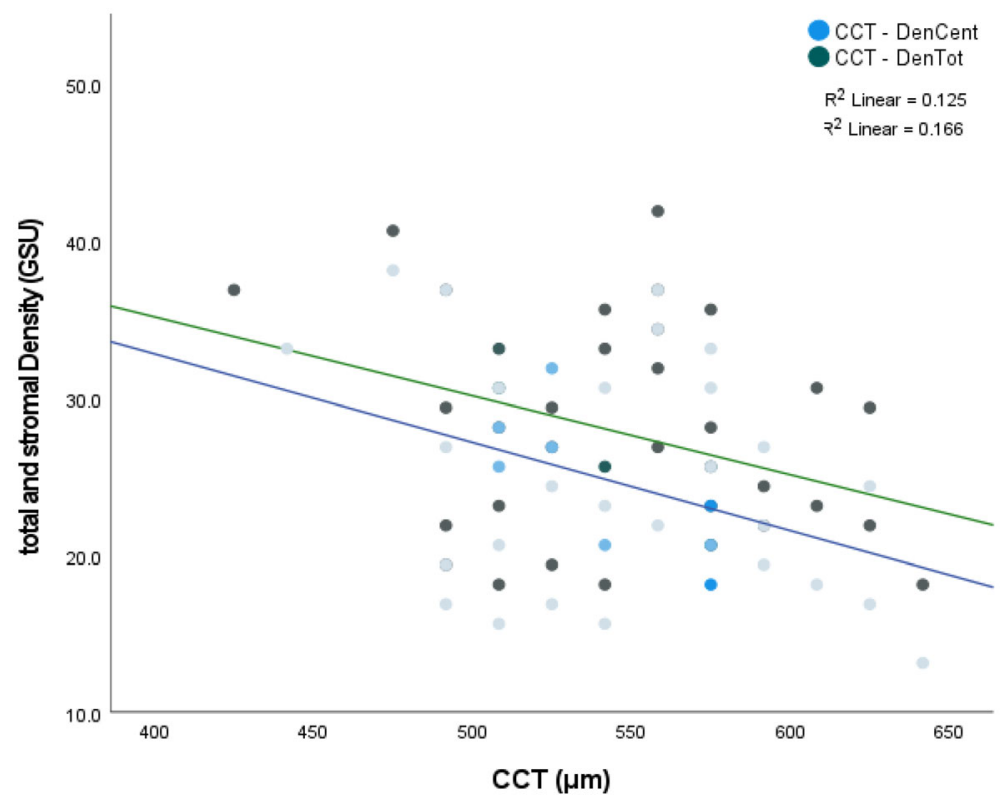

[10-13]. Fernandes et al. showed a difference of $1.34 \mathrm{mmHg}$ on average in the first study aimed at evaluating the accuracy of iCare readings [11]. Chui et al. showed that other factors such as corneal hysteresis and corneal resistance factor are highly correlated with iCare [6]. Thus various studies show different IOP measurements obtained by NCT and GAT. Tonnu et al. showed that at lower IOP readings, NCT significantly underestimated GAT measurements and overestimated them at higher IOP readings
[14]. Jose M. Martinez-de-la-Casa et al. showed a strong agreement between NCT and GAT readings in their study with a mean difference of $-0.1 \mathrm{mmHg}$ [15]. Pagoulatos et al. showed higher GAT than NCT measurements in normal, as well as in vitrectomized eyes with silicone oil endotamponade with mean differences of $0.09 \mathrm{mmHg}$ and $3.34 \mathrm{mmHg}$ respectively [16]. The correlation of IOP measurements of NCT and GAT methods seems to be strongly dependent on different factors such as the impact of heart 
rate, scleral rigidity, as well as the sample size of each study. This reveals that tonometry readings do not always reflect true IOP values but they are clinically similar (within $\pm 2 \mathrm{~mm} \mathrm{Hg}$ ). It has been confirmed to be affected by corneal resistance brought about by variations in corneal biomechanical factors such corneal thickness, curvature, or hysteresis $[5,6,17,18]$.

The present study confirmed the significant correlation between 3 tonometry methods and CCT. Several studies showed several correction factors depended on this association, resulting in a wide range IOPcorrection from 0.12 to $0.7 \mathrm{~mm} \mathrm{Hg} / 10 \mathrm{~mm}$ corneal thickness [5, 8, 17-19]. Using a cornea biomechanical model, Liu and Roberts showed that the corneal rigidity might have a high influence on IOP measurement and that a higher correction factor is needed by increasing Young's modulus [20]. In our measurements, we found a negative correlation between the central corneal thickness and the full-thickness corneal density. This result agreed with that of Patel et al., who used confocal microscopy images in vivo for the measurement of corneal thickness and keratocyte density [21].

Elsheikh et al. demonstrated an age-associated increase in corneal stiffness [22]. They suggested that this could be related to the increase in the age-related non-enzymatic cross-linking between corneal fibrils and is expected to lead to errors in IOP measurement. This age-related tissue stiffness was inducted in an IOP-correction Eq. 7 Based on this finding, Spoerl et al. studied the factor age in the populations of different studies and suggested a new equation adding an age-dependent correction factor in 2012 [23]. In a study with 794 eyes which aimed to describe the normative values of corneal Scheimpflug densitometry, Dhubhghaill et al. showed a significant correlation between age and corneal density [9]. In their study, age was correlated with the total, central layer and 2-6 mm zone with Pearson coefficients of 0.560 , $0.484,0.224$ respectively $(P<0.001)$, although not with the $0-2 \mathrm{~mm}$ zone. High correlations of age with the total and stromal density (Pearson coefficients $>0.75$ ) were found in our study. We believe this could explain the age-related increase in corneal rigidity found in previous studies.

In this study, the multiple regression analysis showed that CCT and the stromal density are significant influential factors of reliable IOP readings obtained using the three tonometry methods, but the stromal density showed significant coefficient for the iCare readings only. It demonstrates that corneas with high density could lead to an underestimation while corneas with low density to an overestimation of IOP readings. This effect was quite more obvious in rebound tonometry (iCare) than Non-contact or Applanation tonometry methods, which provides an explanation for the differences in IOP-correction equations in the previously mentioned studies. This emphasizes the already postulated idea that more corneal biomechanical properties ought to be considered, and a high degree of caution exercised, in any new attempts towards adjusting an IOP-correction equation. These have to be studied in vitro, proved in vivo, and should not treat the cornea simply as a layer of different cells. Funding.

No funding was received to assist with the preparation of this manuscript.

Funding Open Access funding enabled and organized by Projekt DEAL.

\section{Declarations}

Conflict of interest None.

Data availability Not applicable.

Code availability Not applicable.

Open Access This article is licensed under a Creative Commons Attribution 4.0 International License, which permits use, sharing, adaptation, distribution and reproduction in any medium or format, as long as you give appropriate credit to the original author(s) and the source, provide a link to the Creative Commons licence, and indicate if changes were made. The images or other third party material in this article are included in the article's Creative Commons licence, unless indicated otherwise in a credit line to the material. If material is not included in the article's Creative Commons licence and your intended use is not permitted by statutory regulation or exceeds the permitted use, you will need to obtain permission directly from the copyright holder. To view a copy of this licence, visit http://creativecommons.org/licenses/by/4.0/.

\section{References}

1. Goldmann HST (1957) Applanation tonometry. Ophthalmologica 134:221-242. https://doi.org/10.1159/000303213

2. Moseley MJ (1995) Non-contact tonometry. Ophthalmic Physiol Opt 15:S35-37. https://doi.org/10.1046/j.14751313.1995.0150s2S35.x 
3. Domke N, Hager A, Wiegand W (2006) Augeninnendruck und hornhautdicke. Ein vergleich zwischen non-contacttonometrie und applanationstonometrie. Ophthalmologe 103:583-587. https://doi.org/10.1007/s00347-006-1364-1

4. Okafor KC, Brandt JD (2015) Measuring intraocular pressure. Curr Opin Ophthalmol 26:103-109. https://doi.org/10. 1097/ICU.0000000000000129

5. Ehlers N, Bramsen T, Sperling S (1975) Applanation tonometry and central corneal thickness. Acta Ophthalmol 5:34-43. https://doi.org/10.1111/j.1755-3768.1975. tb01135.x

6. W-sang C, Lam A, Chen D et al (2008) The influence of corneal properties on rebound tonometry. Ophthalmology 115:80-84. https://doi.org/10.1016/j.ophtha.2007.03.061

7. Elsheikh A, Alhasso D, Pye D (2009) Goldmann tonometry correction factors based on numerical analysis. J Biomech Eng 131:1-9. https://doi.org/10.1115/1.4000112

8. Qazi Y, Wong G, Monson B et al (2010) Corneal transparency: Genesis, maintenance and dysfunction. Brain Res Bull 81:198-210. https://doi.org/10.1016/j.brainresbull. 2009.05.019

9. Dhubhghaill SN, Rozema JJ, Jongenelen S et al (2014) Normative values for corneal densitometry analysis by scheimpflug optical assessment. Investig Ophthalmol Vis Sci 55:162-168. https://doi.org/10.1167/iovs.13-13236

10. Suman S, Agrawal A, Pal VK et al (2014) Rebound tonometer: Ideal tonometer for measurement of accurate intraocular pressure. J Glaucoma 23:633-637. https://doi. org/10.1097/IJG.0b013e318285fefd

11. Fernandes P, Díaz-Rey JA, Queirós A et al (2005) Comparison of the ICare ${ }^{\circledR}$ rebound tonometer with the Goldmann tonometer in a normal population. Ophthalmic Physiol Opt 25:436-440. https://doi.org/10.1111/j.14751313.2005.00327.x

12. Nakakura S (2018) Icare ${ }^{\circledR}$ rebound tonometers: Review of their characteristics and ease of use. Clin Ophthalmol 12:1245-1253. https://doi.org/10.2147/OPTH.S163092

13. Feng CS, Jin KW, Yi K et al (2015) Comparison of intraocular pressure measurements obtained by rebound, noncontact, and Goldmann applanation tonometry in children. Am J Ophthalmol 160:937-943.e1. https://doi.org/10. 1016/j.ajo.2015.07.029

14. Tonnu PA, Ho T et al (2005) A comparison of four methods of tonometry: method agreement and interobserver variability. Br J Ophthalmol 89(7):847-850. https://doi.org/ 10.1136/bjo.2004.056614

15. Martinez-de-la-Casa JM et al (2011) Performance of the rebound, noncontact and Goldmann applanation tonometers in routine clinical practice. Acta Ophthalmol 89(7):676-680. https://doi.org/10.1111/j.1755-3768.2009. 01774.x

16. Pagoulatos DD et al (2020) Comparison of intraocular pressure using Goldmann applanation tonometry versus non-contact tonometry in eyes with high-viscosity silicone oil. Eur J Ophthalmol 30(3):494-499. https://doi.org/10. $1177 / 1120672119833556$

17. Graf M (1991) Zur Bedeutung der Hornhautdicke bel der Non-Contact-Tonometrie. Kiln Mbl Augenheilk 199:183-186. https://doi.org/10.1055/s-2008-1046068

18. Kohlhaas M, Andreas GB, Eberhard S et al (2006) Effect of central corneal thickness, corneal curvature, and axial length on applanation tonometry. Arch Ophthalmol 124:471-476. https://doi.org/10.1001/archopht.124.4.471

19. Bron AM, Creuzot-Garcher C, Goudeau-Boutillon et al (1999) Falselye levated intraocular pressure due to increased central corneal thickness. Graefe's Arch Clin Exp Ophthalmol 237:220-224. https://doi.org/10.1007/ s004170050222

20. Liu J, Roberts CJ (2005) Influence of corneal biomechanical properties on intraocular pressure measurement: quantitative analysis. J Cataract Refract Surg 31:146-155. https:// doi.org/10.1016/j.jcrs.2004.09.031

21. Patel SV, McLaren JW, Hodge DO et al (2011) Normal human keratocyte density and corneal thickness by confocal microscopy in vivo. Invest Ophthalmol Vis Sci 42:333-339

22. Elsheikh A et al (2007) Assessment of corneal biomechanical properties and their variation with age. Curr Eye Res 3:11-19. https://doi.org/10.1080/02713680601077145

23. Spoerl E, Terai N, Pillunat LE (2012) Age-dependent correction factors for goldmann tonometry. J Glaucoma 21:276-277. 0b013e318252d 382

Publisher's Note Springer Nature remains neutral with regard to jurisdictional claims in published maps and institutional affiliations. 